\title{
Intracoronary propofol does not decrease myocardial contractile function in the dog
}

S.E. Belo PhD MD FRCPC, R. Kolesar MD FRCPC, C.D. Mazer MD FRCPC
$(P \leq 0.05)$. Neither drug had an effect on systolic shortening in the CIRC area, LAD blood flow or diastolic function. The results of this study suggest that propofol does not have an effect on myocardial contractility. The hypotension associated with the intravascular administration of propofol is more likely due to either a direct vascular or a central effect.

L'administration de propofol produit une baisse importante de la pression artérielle. Leétude présente vise à vérifier l'hypothèse selon laquelle la fonction myocardique n'est pas affectée par le propofol et, en conséquence, ne contribue pas à l'effet hypotenseur du propofol. Le propofol est administré à thorax ouvert par perfusion artérielle directe dans la coronaire descendante antérieure gauche (DAG). En plus du débit coronaire, on mesure la pression artérielle moyenne, la fréquence cardiaque, la pression ventriculaire gauche, le $d P / d t$, le lactate régional et l'extraction de l'oxygène. La fonction diastolique est calculée à partir de la constante de temps de la relaxation isovolumétrique et le $d P / d t$. La contractilité est évaluée par la mesure du raccourcissement dans un territoire du myocarde vascularisé par la DAG. Cette mesure est comparée avec le raccourcissement systolique dans le territoire de l'artère circonflexe (CIRC) et avec les autres effets produits par linjection intracoronaire de thiopentone. Ni la perfusion intracoronaire de propofol ni la perfusion de thiopentone ne change la pression artérielle systémique, la fréquence cardiaque, ou la pression télédiastolique du ventricule gauche. Le propofol, à la concentration de 5 ou $10 \mu \mathrm{g} \cdot \mathrm{ml}^{-1}$ ne diminue pas la raccourcissement systolique du territoire étudié perfusé par la DAG alors que le thiopentone $\left(40 \mu \mathrm{g} \cdot \mathrm{ml}^{-1}\right)$ diminue le raccourcissement systolique de 33\% $(P \leq 0,05)$. Aucune des drogues n'affecte la raccourcissement systolique dans le territoire de la CIRC, le débit de la DAG ou la fonction diastolique. Ces résultats montrent l'absence d'effets du propofol sur la contractilité myocardique. L'hypotension provoquée par l'administration de propofol est vraisemblablement due à un effet vasculaire direct ou à un effet central.

Propofol (2,6 diisopropylphenol), an intravenous anaesthetic agent, is in widespread clinical use yet, surprisingly, its precise cardiovascular effects remain controversial. 
Both animal and human studies have consistently shown a decrease in systemic arterial pressure following the iv administration of propofol, but the mechanism of this decrease remains unclear. ${ }^{1,2}$ Several models and methods have been used in an attempt to isolate the effects of propofol on myocardial contractility from the effects on peripheral vascular tone. Thus Mulier et al. ${ }^{3}$ using transoesophageal echocardiography in humans demonstrated a negative inotropic effect and concluded that this was responsible for the hypotensive effect of the drug. In contrast, Boer et al., ${ }^{4}$ during cardiopulmonary bypass in humans, showed that propofol reduced systemic vascular resistance to $68 \%$ of control suggesting that vasodilatation was responsible for the decreased blood pressure during drug administration. Brussel et al. ${ }^{5}$ on the other hand, in a canine model, demonstrated changes in both cardiac output and systemic vascular resistance during propofol administration. These studies have all used systemic propofol administration (intravenous bolus or infusion) and have employed various extrapolated indices of myocardial contractility or vascular tone.

It is important to define clearly propofol's cardiovascular effects since the use of this intravenous anaesthetic appears to be increasing. The recovery characteristics of propofol render it an appropriate agent for day surgery, a setting in which increasing numbers of patients with cardiovascular disease are presenting. A study by Stephan et al. ${ }^{6}$ in ten patients scheduled for elective coronary artery bypass surgery, found myocardial lactate production in one patient leading the authors to suggest that propofol may lead to myocardial ischaemia in patients with coronary artery disease. Knowledge of the effect of propofol on peripheral vascular resistance versus myocardial contractility would allow us to decide which patients may show detrimental effects from propofol administration and may alter our use of the drug. Treatment of hypotension associated with propofol administration would be facilitated by knowledge of the mechanism responsible for its production and the contribution of this effect to myocardial ischaemia potentially prevented.

The current study, unlike many previous investigations, was designed to evaluate the direct effect of propofol on myocardial contractility. Propofol was administered as an intracoronary infusion in an in situ canine model and the effect on regional systolic shortening in the perfused area was evaluated. In this way the direct effect on the myocardium could be determined in the absence of any effect on the peripheral vasculature. Additionally, the effects on coronary blood flow, diastolic function and regional oxygen and lactate extraction were determined. The effect of propofol was compared with that of thiopentone, a common induction agent, which is known to decrease myocardial contractility. ${ }^{1,2}$

\section{Methods}

\section{Surgical preparation}

All experiments were performed in accordance to the standards of the Animal Care Committee, St. Michael's Hospital, the University of Toronto Guidelines and the Animals for Research Act. Sixteen mongrel dogs (20-46 $\mathrm{kg}$ ) were anaesthetized with sodium thiopentone 10 $\mathrm{mg} \cdot \mathrm{kg}^{-1} \dot{\nu}, \alpha$-chloralose $100 \mathrm{mg} \cdot \mathrm{kg}^{-1} \dot{i}$, and morphine sulphate $3 \mathrm{mg} \cdot \mathrm{kg}^{-1} \mathrm{im}$. Following tracheal intubation, ventilation was controlled to maintain normocarbia. Anaesthesia was continued with an infusion of $\alpha$ chloralose $20 \mathrm{mg} \cdot \mathrm{kg}^{-1} \cdot \mathrm{hr}^{-1}$ and neuromuscular blockade was maintained with pancuronium bromide $5 \mathrm{mg}$ $i v$. An eight inch $14 \mathrm{G}$ catheter was inserted into the aorta via the left carotid artery and connected to a Statham transducer (P23Db) for continuous blood pressure monitoring and blood sampling. The heart was exposed through a left thoracotomy incision in the 5th interspace and suspended in a pericardial sling. A catheter tip pressure transducer (Millar) was advanced into the left ventricle through the left atrium to measure left ventricular pressure and derive $d \mathrm{P} / d \mathrm{t}$. Regional ventricular function was evaluated by measuring systolic shortening using piezoelectric ultrasonic crystals. A pair of $5 \mathrm{MHz}$ crystals (Dimension 3) were implanted 7-15 $\mathrm{mm}$ apart in the midmyocardium of the areas supplied by the left anterior descending (LAD) and circumflex (CIRC) coronary arteries and oriented perpendicular to the long axis of the heart. Catheters were inserted into two epicardial veins, one draining the LAD and the other the CIRC perfusion bed, to allow for venous blood sampling. Patency was maintained by a continuous microdrip infusion of heparinized saline. Body surface electrodes were used to monitor the ECG. Systemic anticoagulation was achieved with heparin 400 units $\cdot \mathrm{kg}^{-1}$ and maintained with heparin 200 units $\cdot \mathrm{kg}^{-1} \cdot \mathrm{hr}^{-1}$. The LAD was cannulated with a $3 \mathrm{~mm}$ DLP flexible vessel catheter (modified in our laboratory) and perfused by an autoperfusion circuit from the left carotid artery. The cannula incorporated a $22 \mathrm{G}$ catheter in the lumen to measure coronary perfusion pressure (CPP) at the tip of the cannula. Care was taken to ensure that a pressure drop did not exist between the circuit and the tip of the cannula. In some experiments, coronary perfusion pressure was matched to arterial blood pressure manually using a Masterflex roller pump which was placed in-line with the perfusion circuit. In this system, flow was adjusted such that CPP equalled MAP. The circuit also contained an in-line Transonics flowmeter to measure coronary blood flow and distal injection ports for drug administration. Animals were allowed to stabilize for $30 \mathrm{~min}$ following instrumentation (Figure). 


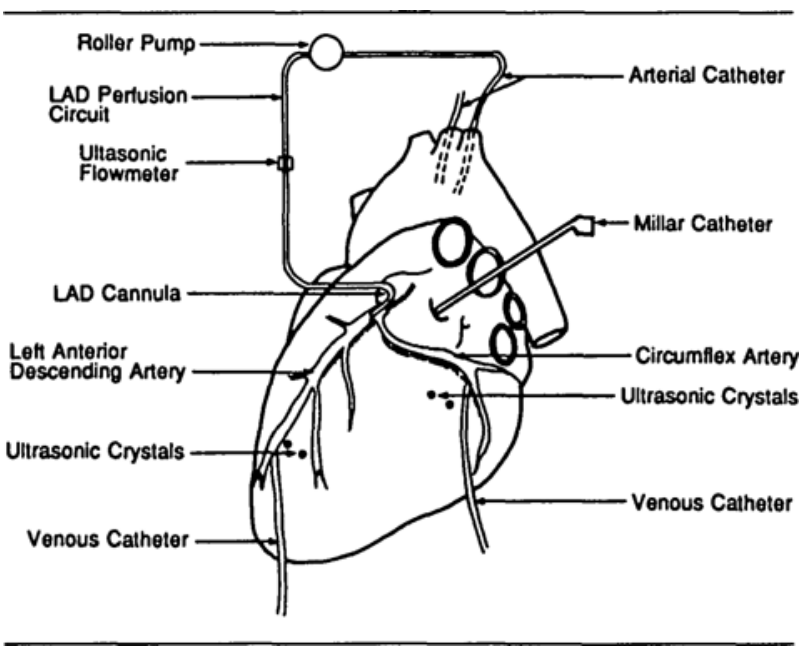

FIGURE Surgical preparation.

\section{Data collection}

Arterial blood pressure, left ventricular pressure, its first derivative $d \mathrm{P} / d t, \mathrm{CPP}$, and LAD blood flow were continuously measured and displayed on a Gould ES1000 physiological recorder. Analog signals from the crystals, calibrated through a sonomicrometer (Triton Technology), were continuously monitored on an oscilloscope (Tektronics) and also displayed on the Gould recorder. Analog signals from the Gould recorder were digitalized using a Data Translation DT2801 A/D Conversion board connected to an IBM AT microcomputer and stored for later analysis. Data for each measurement period were collected and averaged for ten beats. Systolic shortening was calculated as follows: [(end diastolic length - end systolic length)/end diastolic length] $\times 100$. End diastole was defined as the onset of positive $d \mathrm{P} / d t$ end systole was defined as $20 \mathrm{msec}$ before the maximally negative $d \mathrm{P} / d \mathrm{t}$. All values were normalized to a precannulation control value of $100 \%$. Diastolic function of the myocardium was evaluated according to the method described by Pagel et al. ${ }^{7}$ Briefly, the time constant $\left(\mathrm{T}_{0}\right)$ of isovolumetric relaxation was calculated from the left ventricular pressure and $d \mathrm{P} / d t$; curves using a monoexponential curve fit. Additionally a second time constant $\left(T_{n}\right)$ which does not assume that ventricular pressure declines to a zero asymptote, ${ }^{8}$ was also calculated. Simultaneous arterial and coronary venous blood samples were drawn for measurement of oxygen and lactate extraction. The arterial blood gas samples were immediately processed using the IL1304 Blood Gas Analyzer. Blood lactate samples were immediately deproteinized with cold perchloric acid, centrifuged, and separated. The supernatant was frozen and later analyzed using an enzymatic spectrophotometric technique. Oxygen and lactate extractions were calculated as: [(arterial content - venous content)/arterial content] $\times 100$.

\section{Experimental protocol}

Baseline systolic shortening and haemodynamic data were collected after stabilization of the experimental preparation. Venous and arterial blood samples were drawn for determination of $\mathrm{pH}, \mathrm{PCO}_{2}, \mathrm{PO}_{2}$, haemoglobin, oxygen saturation and lactate. These measurements were repeated $30 \mathrm{~min}$ after cannulation of the LAD (control). The animals then received intracoronary infusions of either propofol $(n=10)$ or thiopentone $(n=6)$. Based on the measured coronary blood flow, the drugs were delivered to achieve a final intracoronary concentration of propofol $5 \mu \mathrm{g} \cdot \mathrm{ml}^{-1}$ and $10 \mu \mathrm{g} \cdot \mathrm{ml}^{-1}$ or thiopentone $20 \mu \mathrm{g} \cdot \mathrm{ml}^{-1}$ and $40 \mu \mathrm{g} \cdot \mathrm{ml}^{-1}$. Each animal received only one drug; the low dose given first for $30 \mathrm{~min}$, discontinued for $30 \mathrm{~min}$ and followed by administration of the higher dose for $30 \mathrm{~min}$. Haemodynamic data, systolic shortening, oxygen extraction, and lactate extraction were measured at 5, 10, 15, and $30 \mathrm{~min}$ of drug administration; however, for the sake of clarity, only the data at $30 \mathrm{~min}$ of drug administration has been reported. These measurements were repeated $30 \mathrm{~min}$ after discontinuation of the drug (recovery).

\section{Statistical analysis}

Data were analyzed using repeated measures analysis of variance (SAS Institute). Significant results were further analyzed using Duncan's or Tukey's multiple range test. A $P$ value $<0.05$ was considered significant.

\section{Results}

Cannulation and perfusion of the LAD by means of an autoperfusion circuit from the carotid artery did not alter baseline heart rate, mean arterial pressure, left ventricular pressure, $d \mathrm{P} / d t$, left ventricular end diastolic pressure (LVEDP), systolic shortening, lactate or oxygen extraction.

The intracoronary administration of propofol at either dose did not produce any changes in mean arterial pressure, heart rate, or left ventricular end diastolic pressure. Thiopentone also did not produce any significant effect on the haemodynamic variables although MAP tended to be decreased and LVEDP increased (Table I).

Compared with control values, systolic shortening in the CIRC region did not change during either propofol or thiopentone administration. In the LAD region, propofol did not produce any change in systolic shortening at either concentration. In contrast to this, thiopentone produced a dose-dependent decrease in systolic shortening; this decrease reached $33 \%$ at the higher concentration $(P<0.05)$ (Table II). No differences were found when end diastolic lengths in the LAD or CIRC region, as another index of preload, were compared to control values. 
TABLE I Haemodynamic variables

\begin{tabular}{lllr}
\hline & $\begin{array}{l}M A P \\
(\mathrm{mmHg})\end{array}$ & $H R(b p m)$ & $\begin{array}{l}\text { LEEDP } \\
(\mathrm{mmHg})\end{array}$ \\
\hline Control $(n=10)$ & $99 \pm 15$ & $116 \pm 37$ & $10.1 \pm 3.7$ \\
Propofol $5 \mu \mathrm{g} \cdot \mathrm{ml}^{-1}$ & $95 \pm 13$ & $120 \pm 39$ & $9.7 \pm 3.6$ \\
Propofol $10 \mu \mathrm{g} \cdot \mathrm{ml}^{-1}$ & $96 \pm 14$ & $116 \pm 37$ & $8.7 \pm 1.9$ \\
Recovery & $97 \pm 15$ & $119 \pm 40$ & $8.8 \pm 1.6$ \\
Control $(n=6)$ & $96 \pm 25$ & $105 \pm 28$ & $7.7 \pm 1.9$ \\
Thiopentone $20 \mu \mathrm{g} \cdot \mathrm{ml}^{-1}$ & $91 \pm 19$ & $102 \pm 29$ & $8.1 \pm 3.0$ \\
Thiopentone $40 \mu \mathrm{g} \cdot \mathrm{ml}^{-1}$ & $84 \pm 20$ & $102 \pm 36$ & $8.5 \pm 4.0$ \\
Recovery & $85 \pm 15$ & $98 \pm 22$ & $7.4 \pm 4.2$ \\
\hline
\end{tabular}

Mean \pm SD.

$P=$ NS vs control.

TABLE II Systolic shortening (\%)

\begin{tabular}{lll}
\hline & $L A D$ & $C I R C$ \\
\hline Control $(n=10)$ & $15.6 \pm 7.5$ & $11.7 \pm 4.6$ \\
& $(100 \%)$ & $(100 \%)$ \\
Propofol $5 \mu \mathrm{g} \cdot \mathrm{ml}^{-1}$ & $15.7 \pm 7.6$ & $12.0 \pm 5.5$ \\
& $(100 \%)$ & $(103 \%)$ \\
Propofol $10 \mu \mathrm{g} \cdot \mathrm{ml}^{-1}$ & $13.6 \pm 7.9$ & $10.4 \pm 4.8$ \\
& $(87 \%)$ & $(89 \%)$ \\
Recovery & $14.5 \pm 8.4$ & $8.9 \pm 5.1$ \\
& $(92 \%)$ & $(76 \%)$ \\
Control $(n=6)$ & & \\
& $15.7 \pm 8.0$ & $13.0 \pm 5.0$ \\
Thiopentone $20 \mu \mathrm{g} \cdot \mathrm{ml}^{-1}$ & $(100 \%)$ & $(100 \%)$ \\
& $14.8 \pm 8.4$ & $12.6 \pm 5.0$ \\
Thiopentone $40 \mu \mathrm{g} \cdot \mathrm{ml}^{-1}$ & $(89 \%)$ & $(97 \%)$ \\
& $10.5 \pm 9.5 *$ & $11.1 \pm 6.6$ \\
Recovery & $(67 \%)$ & $(85 \%)$ \\
& $13.2 \pm 8.5$ & $9.7 \pm 4.2$ \\
& $(84 \%)$ & $(75 \%)$ \\
\hline
\end{tabular}

Mean \pm SD.

$* P<0.05$.

Diastolic function during propofol and thiopentone is outlined in Table III. Neither $T_{0}$ nor $T_{n}$ were altered during propofol or thiopentone administration.

Results for metabolic indices are shown in Table IV. Propofol produced a decrease in oxygen extraction in both the LAD and CIRC areas. This was in contrast to thiopentone which did not alter oxygen extraction in either region of the myocardium. Lactate extraction did not change during propofol infusion; it was, however, significantly decreased during high-dose thiopentone infusion.

There was no effect of either drug on coronary blood flow (Table V).

\section{Discussion}

This study demonstrates that propofol, at the concentrations studied, in an in situ canine model, does not produce
TABLE III Diastolic function

\begin{tabular}{llll}
\hline & $T_{0}$ & $T_{n}$ & $\begin{array}{l}\text { Peak neg } \\
d P / d t\end{array}$ \\
\hline Control $(n=10)$ & $37.7 \pm 11.8$ & $37.4 \pm 6.8$ & $1742 \pm 615$ \\
Propofol $5 \mu \mathrm{g} \cdot \mathrm{ml}^{-1}$ & $40.1 \pm 15.8$ & $41.0 \pm 10.0$ & $1659 \pm 577$ \\
Propofol $10 \mu \mathrm{g} \cdot \mathrm{ml}^{-1}$ & $38.5 \pm 13.1$ & $43.3 \pm 12.1$ & $1585 \pm 524$ \\
& & & \\
Control $(n=6)$ & $31.2 \pm 11.4$ & $40.6 \pm 18.5$ & $1803 \pm 673$ \\
Thiopentone $20 \mu \mathrm{g} \cdot \mathrm{ml}^{-1} 34.2 \pm 6.7$ & $51.9 \pm 13.5$ & $1621 \pm 594$ \\
Thiopentone 40 $\mathrm{\mu g} \cdot \mathrm{ml}^{-1} 34.6 \pm 12.7$ & $50.7 \pm 18.3$ & $1350 \pm 188$ \\
\hline Mean $\pm \mathrm{SD}$. & & & \\
$P=\mathrm{NS}$ vs control. & & &
\end{tabular}

direct depression of myocardial contractility. The study differed from others in that systolic shortening (SS) was used as a measure of regional contractility. Additionally, the drug was administered by direct intracoronary infusion and the regional response of the area of myocardium exposed to the drug (LAD region) was compared with a control area of the myocardium (CIRC region). In this way, effects on the peripheral circulation were unable to confound direct cardiac effects.

The usefulness and validity of \%SS is predicated on two conditions: that \%SS reflects myocardial contractility and that changes in \%SS are due solely to drug effects. Systolic shortening is dependent on both preload and afterload; however in this study no changes in loading conditions, as measured by left ventricular pressure (an index of afterload) or end diastolic segment length (an index of preload), were observed. Therefore, changes in \%SS can be attributed solely to changes in myocardial contractility. The second condition requires that the demand for myocardial work was unchanged during drug administration. Lack of significant changes in heart rate or MAP suggests that this condition had also been met.

The results are consistent with several animal and human studies which have failed to identify a negative inotropic effect attributable to propofol. Goodchild and Serrao ${ }^{9}$ used left ventricular $d \mathbf{P} / d \mathrm{t}$ in a canine model to assess myocardial contractility. Under conditions of constant preload (pulmonary artery wedge pressure) and moderate plasma levels of propofol $\left(<10 \mu \mathrm{g} \cdot \mathrm{ml}^{-1}\right)$, no change in myocardial function was observed. deHert et al. ${ }^{10}$ studied changes in segment length to assess function in dog myocardium. In both normal and ischaemic myocardium exposed to propofol, they observed a much greater decrease in end diastolic length (an indicator of preload) than in systolic shortening. Ismail $e t$ al., ${ }^{11}$ in a canine model similar to the one used in the present study, carried out intracoronary infusions and measured segment length. As in our study, clinical concentrations of propofol had no direct effect on contractility. In humans, Lepage et al. ${ }^{12}$ relied on global ejection fraction 


\begin{tabular}{|c|c|c|c|c|}
\hline & \multicolumn{2}{|c|}{ Oxygen extraction $\%$} & \multicolumn{2}{|c|}{ Lactate extraction $\%$} \\
\hline & $L A D$ & CIRC & $L A D$ & CIRC \\
\hline Control $(n=10)$ & $40.4 \pm 9.2$ & $42.2 \pm 9.2$ & $30.8 \pm 20.4$ & $33.0 \pm 18.2$ \\
\hline Propofol $5 \mu \mathrm{g} \cdot \mathrm{ml}^{-1}$ & $34.8 \pm 8.6^{*}$ & $37.1 \pm 8.7^{*}$ & $31.5 \pm 21.2$ & $25.6 \pm 23.1$ \\
\hline Propofol $10 \mu \mathrm{g} \cdot \mathrm{mb}^{-1}$ & $32.4 \pm 9.0^{*}$ & $38.6 \pm 8.6$ & $26.1 \pm 20.8$ & $23.7 \pm 25.5$ \\
\hline Control $(n=6)$ & $36.5 \pm 7.7$ & $41.1 \pm 7.9$ & $34.8 \pm 10.1$ & $41.9 \pm 10.0$ \\
\hline Thiopentone $20 \mu \mathrm{g} \cdot \mathrm{ml}^{-1}$ & $34.4 \pm 7.9$ & $37.5 \pm 9.6$ & $28.1 \pm 10.7$ & $35.8 \pm 14.5$ \\
\hline Thiopentone $40 \mu \mathrm{g} \cdot \mathrm{ml}^{-1}$ & $31.5 \pm 7.4$ & $40.7 \pm 7.3$ & $23.1 \pm 8.6^{*}$ & $30.8 \pm 13.5$ \\
\hline
\end{tabular}

Mean \pm SD

$* P<0.05$.

TABLE V Coronary blood flow $\left(\mathrm{ml} \cdot \mathrm{min}^{-1}\right)$

\begin{tabular}{ll}
\hline Control $(n=10)$ & $30.6 \pm 10.1$ \\
Propofol $5 \mu \mathrm{g} \cdot \mathrm{ml}^{-1}$ & $31.6 \pm 13.7$ \\
Propofol $10 \mu \mathrm{g} \cdot \mathrm{ml}^{-1}$ & $31.7 \pm 10.3$ \\
& \\
Control $(n=5)$ & $27.8 \pm 8.4$ \\
Thiopentone $20 \mu \mathrm{g} \cdot \mathrm{ml}^{-1}$ & $28.8 \pm 7.0$ \\
Thiopentone $40 \mu \mathrm{g} \cdot \mathrm{ml}^{-1}$ & $35.0 \pm 7.3$ \\
\hline
\end{tabular}

and peak systolic/end systolic volume ratio (determined by radionuclide angiography) to assess contractility. In patients given propofol, a reduction in indices of preload were observed while no changes in indices of contractility or after load were detected. In a study in humans with temporary artificial hearts, where cardiac output is preload independent and constant, Rouby et al. ${ }^{13}$ found that blood pressure decreased by $39 \%$ while systemic vascular resistance decreased by $44 \%$ during propofol administration. In a recent study, Muzi et al. ${ }^{14}$ using venous occlusion plethysmography demonstrated changes in venous compliance during propofol administration in humans suggesting a dominant effect on venous tone. Thus, results from several models concur with our findings that propofol does not have a negative inotropic effect but does alter systemic vascular resistance and/or venous tone.

Nevertheless, other investigators have drawn different conclusions. Coetzee et al. ${ }^{15}$ used the end systolic pressure volume relationship to assess propofol's effect on myocardial contractility in an open-chested pig model and showed a negative inotropic effect. Noteworthy in this study was that propofol did not produce a decrease in blood pressure and peripheral resistance increased. When the drug was discontinued for up to $60 \mathrm{~min}$, "contractility" did not recover. Brussel et al. ${ }^{5}$ using a needle force probe implanted in the left ventricle of anaesthetized dogs found that the $\dot{\boldsymbol{v}}$ administration of propofol $2.5 \mathrm{mg} \cdot \mathrm{kg}^{-1}$ was associated with a decrease in left ventricular systolic pressure and $d \mathrm{~F} / d \mathrm{t}_{\max }$. However, the signals generated from the force probes were highly dependent on the orientation of the fibres relative to the ventricular surface and there was also a substantial $12 \%$ decrease in systemic vascular resistance in addition to the changes in $d F / d t$. Stowe et al. ${ }^{16}$ infused isolated guinea pig hearts with multiple intravenous anaesthetics, including propofol, and studied their effect on contractility by measuring $d \mathrm{P} / d t_{\max }$. It was found that propofol reduced myocardial contractility by $50 \%$ but this was at a perfusate concentration of $91 \mu \mathrm{M}$, a concentration that was reported to be approximately 1.8 times the concentration reported in humans after induction $(50 \mu \mathrm{M})$. Mulier et al. ${ }^{3}$ demonstrated reduced myocardial contractility due to propofol in humans by using transoesophageal echocardiography (TEE). He evaluated contractility by measuring the systemic arterial pressure/ end systolic volume ratio. However, there was marked variability in the calculated values of stroke volume and cardiac output and the clinical relevance is difficult to assess. In another TEE study, Gauss et al. ${ }^{17}$ examined propofol's effect on contractility by measuring both the systolic pressure/end systolic diameter ratio and systolic shortening. In this study an induction dose of propofol resulted in both reduced contractility and afterload; in contrast, an induction dose of thiopentone resulted in only modestly reduced contractility.

Reconciliation of these various and conflicting conclusions is difficult. Prominent differences among these studies include: experimental model (animal vs human, in vivo vs in vitro), method of assessing myocardial contractility, prevalence of cardiac disease in the study population, non-uniform pre-medication (including cardiac medications), varying background anaesthetics, extent of isolation of peripheral vascular and cardiac effects, and varying statistical treatments.

\section{Drug dosages}

Target concentrations of the study drugs were obtained from human pharmacokinetic studies. I The lower of the 
two plasma concentrations for each drug $\left(5 \mu \mathrm{g} \cdot \mathrm{ml}^{-1}\right.$ propofol and $20 \mu \mathrm{g} \cdot \mathrm{ml}^{-1}$ thiopentone) were reported to maintain unconsciousness (sleep or hypnosis) in $95 \%$ of subjects $\left(E D_{95}\right)$. One study reported the induction dose of propofol in the dog to be $5 \mathrm{mg} \cdot \mathrm{kg}^{-1}$ compared with $2.5 \mathrm{mg} \cdot \mathrm{kg}^{-1}$ in humans. ${ }^{18}$ If propofol was eliminated in a manner similar to humans, one might expect a plasma concentration no greater than $10 \mu \mathrm{g} \cdot \mathrm{ml}^{-1}$, the higher of the two doses used in the present study, to maintain hypnosis in the dog. The concentrations of propofol for this study were chosen to achieve clinically relevant levels and were compared with equipotent levels of thiopentone.

The high-dose target concentrations $\left(\mathrm{ED}_{95} \times 2\right)$ may represent concentrations that are seldom achieved in clinical practice. If this were so, the reduced myocardial contractility observed at these concentrations may be inconsequential. Reduced myocardial contractility as a result of high-dose thiopentone has been described previously; ${ }^{19}$ that the present experimental model confirms this finding validates the model as being capable of detecting important changes in myocardial function.

\section{Other findings}

This study also demonstrated that neither propofol nor thiopentone altered diastolic function, i.e., diastolic relaxation. This is not unexpected since diastolic function as characterized by relaxation time constants evaluates global function whereas the drugs would have regional effects only since they were administered by direct intracoronary infusion. Lactate extraction was decreased during infusion of high-dose thiopentone. This decrease could result from ischaemia, increased coronary blood flow or alternatively from decreased lactate utilization by non-ischaemic myocardium. The ECG, although lacking sensitivity, did not show any evidence of ischaemia and coronary blood flow was shown to be unchanged thus suggesting that decreased metabolic requirements secondary to decreased contractility were responsible for the decreased lactate extraction seen with thiopentone. Nevertheless the large variability in the weights of the animals and possibly in the hearts may have masked some of the smaller changes in coronary blood flow. Lactate extraction was largely unchanged during infusion of both low-dose and high-dose propofol. Oxygen extraction on the other hand was significantly decreased during infusion of both doses of propofol while it remained unchanged during thiopentone administration.

\section{Summary}

This study shows that propofol does not produce direct depression of myocardial contractility in the dog. These results are consistent with other recent studies which sug- gest that the hypotension associated with intravenous propofol administration may be due primarily to its effect on preload. However, it does not preclude a possible effect on central cardiovascular control centres.

\section{Acknowledgements}

The authors would like to thank Colin Kay, Dan Wigglesworth and Kerry McClenaghan for their expert technical assistance and computer analysis of the data and Dr. Halperin's laboratory for lactate analysis. Propofol was kindly provided by ICI Pharma.

\section{References}

1 White PF. Propofol: pharmacokinetics and pharmacodynamics. Seminars in Anesthesia 1988; 7(Suppl): 4-20.

2 Park WK, Lynch C 3rd. Propofol and thiopental depression of myocardial contractility. A comparative study of mechanical and electrophysiologic effects in isolated guinea pig ventricular muscle. Anesth Analg 1992; 74 : 395-405.

3 Mulier JP, Wouters PF, Van Aken H, Vermaut G, Vandermeersch $E$. Cardiodynamic effects of propofol in comparison with thiopental: assessment with a transesophageal echocardiographic approach. Anesth Analg 1991; 72 : 28-35.

4 Boer F, Bovill JG, Ros P, van Ommen H. Effect of thiopentone, etomidate and propofol on systemic vascular resistance during cardiopulmonary bypass. $\mathrm{Br} \mathbf{J}$ Anaesth 1991; 67: 69-72.

5 Brüssel T, Theissen JL, Vigfusson G, Lunkenheimer PP, Van Aken H, Lawin P. Hemodynamic and cardiodynamic effects of propofol and etomidate: negative inotropic properties of propofol. Anesth Analg 1989; 69: 35-40.

6 Stephan H, Sonntag H, Schenk HD, Kettler D, Khambatta $H J$. Effects of propofol on cardiovascular dynamics, myocardial blood flow and myocardial metabolism in patients with coronary artery disease. Br J Anaesth 1986; 58: 969-75.

7 Pagel PS, Kampine JP, Schmeling WT, Warltier DC. Alteration of left ventricular diastolic function by desflurane, isoflurane, and halothane in the chronically instrumented dog with autonomic nervous system blockade. Anesthesiology 1991; 74: 1103-14.

8 Weiss $J L$, Frederiksen JW, Weisfeldt ML. Hemodynamic determinants of the time-course of fall in canine left ventricular pressure. J Clin Invest 1976; 58: 751-60.

9 Goodchild CS, Serrao JM. Cardiovascular effects of propofol in the anaesthetized dog. $\mathrm{Br} \mathrm{J}$ Anaesth 1989; 63: 87-92.

10 De Hert SG, Vermeyen KM, Adriaensen HF. Influence of thiopentone, etomidate, and propofol on regional myocardial function in the normal and acute ischemic heart segment in dogs. Anesth Analg 1990; 70: 600-7. 
11 Ismail EF, Kim S-J, Salem MR, Crystal GJ. Direct effects of propofol on myocardial contractility in in situ canine hearts. Anesthesiology 1992; 77: 964-72.

12 Lepage J-Y, Pinaud ML, Hélias JH, et al. Left ventricular function during propofol and fentanyl anesthesia in patients with coronary artery disease: assessment with a radionuclide approach. Anesth Analg 1988; 67: 949-55.

13 Rouby JJ, Andreev A, Léger P, et al. Peripheral vascular effects of thiopental and propofol in humans with artificial hearts. Anesthesiology 1991; 75: 32-42.

14 Muzi M, Berens RA, Kampine JP, Ebert TJ. Venodilation contributes to propofol-mediated hypotension in humans. Anesth Analg 1992; 74: 877-83.

15 Coetzee A, Fourie P, Coetzee J, et al. Effect of various propofol plasma concentrations on regional myocardial contractility and left ventricular afterload. Anesth Analg 1989; 69: 473-83.

16 Stowe DF, Bosnjak ZJ, Kampine JP. Comparison of etomidate, ketamine, midazolam, propofol, and thiopental on function and metabolism of isolated hearts. Anesth Analg 1992; 74: 547-58.

17 Gauss A, Heinrich H, Wilder-Smith $O H G$. Echocardiographic assessment of the haemodynamic effects of propofol: a comparison with etomidate and thiopentone. Anaesthesia 1991; 46: 99-105.

18 Watkins $S B$, Hall LW, Clarke KW. Propofol as an intravenous anaesthetic agent in dogs. Vet Rec 1987; 120: 326-9.

19 Reves JG, Kissin I. Intravenous anaesthetics. In: Kaplan JA (Ed.). Cardiac Anesthesia, Vol 2, New York: Grune \& Stratton Inc., 1983; 5-6. 